Research Article, Issue 1
Analytical Methods in Environmental Chemistry Journal
AMECJ

\title{
Solid phase extraction and determination of indium using multi-walled carbon nanotubes modified with magnetic nanoparticles
}

\author{
Ehsan Zolfonoun ${ }^{\text {a, }}{ }^{*}$ \\ a Material and Nuclear Fuel Research school, Nuclear Science and Technology Research Institute, Tehran, Iran
}

\section{A R T I C L E I N F O:}

Received 18 Aug 2018

Revised form 20 Oct 2018

Accepted 28 Nov 2018

Available online 31 Dec 2018

Keywords:

Indium

Preconcentration

Carbon nanotubes

$\mathrm{Fe}_{3} \mathrm{O}_{4}$ nanoparticles

\begin{abstract}
A B S T R A C T
In this work MWCNTs- $\mathrm{Fe}_{3} \mathrm{O}_{4}$ nanocomposite was used as an adsorbent for extraction and preconcentration of indium from aqueous solutions. The magnetic MWCNTs with adsorbed analytes were easily separated from the aqueous solution by applying an external magnetic field. After elution of the adsorbed analytes, the concentration of indium was determined using inductively coupled plasma optical emission spectrometry determination. The effects of $\mathrm{pH}$, sorbent amount, eluent type, chelating reagent concentration, sample volume, and time on the recovery of the $\operatorname{In}(\mathrm{III})$ were investigated. Moreover, under the optimum conditions, the detection limit for In(III) was $0.28 \mu \mathrm{g} \mathrm{L}^{-1}$. The precision of the method, evaluated as the relative standard deviation obtained by analyzing a series of ten replicates, was $3.1 \%$. Ultimately, the method was successfully applied for the determination of In(III) in .environmental water samples
\end{abstract}

\section{Introduction}

Indium is an important element in the semiconductor industry, in the nuclear studies and in the production of high purity materials [1]. Indium and its compounds have numerous industrial applications including the manufacture of liquid crystal displays (LCD), semiconductors, low-temperature solders, and infrared photodetectors [2]. Also, indium compounds damage the heart, kidney, and liver. Thus, there is a need for specific and precise determination of indium traces in environmental

\footnotetext{
*Corresponding author: Email: ezolfonoun@aeoi.org.ir https://doi.org/10.24200/amecj.v1.i01.14
}

and biological samples. The quantification of metal ions in various matrices has been performed by different techniques, including spectrophotometry, atomic absorption spectrometry (AAS), and inductively coupled plasma optical emission spectrometry (ICP-OES) [3]. In addition, using the mentioned methods directly for determining indium at very low concentrations is difficult because of insufficient sensitivity of this technique, as well as the matrix interferences which occur in real samples, and an initial sample pretreatment, such as preconcentration of the analyses (or analytes) and matrix separation, is often necessary [4]. Solid 
phase extraction (SPE) is a routine extraction method for preconcentration of organic and inorganic analytes. This technique reduces solvent usage and exposure, disposal costs, and extraction time. In addition, based on the references, [5] and [6], various adsorbents have been used for adsorption of analytes in SPE methods.

Magnetic nanoparticles, mainly including $\mathrm{Fe}_{3} \mathrm{O}_{4}$ nanoparticles, received increasing attention in the recent years due to its unique properties and high potential applications in various fields such as cell separation, magnetically assisted drug delivery, enzyme immobilization, and protein separation [7, 8].. Recently, using magnetic nanoparticles for extraction of analytes in SPE methods is gaining research interest $[9,10]$. In addition, multi-walled carbon nanotubes (MWCNTs) have received great attention due to their exceptional electronic, mechanical, thermal, chemical properties, and significant potential applications in many fields [11]. Owing to their large surface area and high reactivity, MWCNTs based adsorbents have been used for solid phase extraction and preconcentration of organic compounds and metal ions [12,13]. The decoration of MWCNTs with various compounds can modify their physicochemical properties. Also, this character makes them more suitable for chemical and biological applications. Functionalizing MWCNTs with magnetic nanoparticles can combine the features of magnetic nanoparticles and MWCNTs, which may result in materials with potential applications in biological labelling, drug delivery, and magnetic storage media $[14,15]$. In this paper, a magnetic solid phase extraction method based on Multi-walled carbon nanotubes decorated with $\mathrm{Fe}_{3} \mathrm{O}_{4}$ nanoparticles is developed for the extraction and preconcentration of trace amounts of indium, prior to their determination by ICP-OES.

\section{Experimental Procedure}

\subsection{Reagents}

All reagents used were of analytical grade and were used as supplied. $\mathrm{HNO}_{3}$, ammonia solution, $\mathrm{FeCl}_{3} \cdot 6 \mathrm{H}_{2} \mathrm{O}$, and $\mathrm{FeCl}_{2} \cdot 4 \mathrm{H}_{2} \mathrm{O}$, were purchased from Merck (Germany). MWCNTs (purity $>$ 95\%) were obtained from Sigma-Aldrich. Standard stock solution $\left(1000 \mu \mathrm{g} \mathrm{mL}^{-1}\right)$ of $\mathrm{In}(\mathrm{III})$ was prepared by dissolving appropriate amounts of $\operatorname{In}\left(\mathrm{NO}_{3}\right)_{3}$ in water. A solution of $1.0 \times 10^{-3} \mathrm{~mol} \mathrm{~L}^{-1}$ quinalizarine (Merck) was prepared by dissolving appropriate amounts of this reagent in $0.01 \mathrm{~mol} \mathrm{~L}^{-1} \mathrm{NaOH}$ (Merck).

\subsection{Instrumentation}

All the measurements were carried out using a Perkin Elmer (Optima 7300 DV) simultaneous ICP-OES coupled to a concentric nebulizer and equipped with a charge coupled device (CCD) detector. Moreover, Metrohm model 744 digital $\mathrm{pH}$ meter, equipped with a combined glasscalomel electrode, was employed for the $\mathrm{pH}$ adjustments.

\subsection{Preparation of $M W C N T S-\mathrm{Fe}_{3} \mathrm{O}_{4}$ nanocomposite} MWCNTs- $\mathrm{Fe}_{3} \mathrm{O}_{4}$ nanocomposite was synthesized according to the previously reported methods, which were mentioned in the references, [14] and [15]. First, MWCNTs were dispersed in concentrated nitric acid for 4 hours with ultrasonic treatment. Then purified MWCNTs were separated by filtering. Afterwards, they washed repeatedly with distilled water followed by ethanol and dried at $50{ }^{\circ} \mathrm{C}$. The MWCNTs- $\mathrm{Fe}_{3} \mathrm{O}_{4}$ nanocomposite was prepared by chemical coprecipitation method. First, $\mathrm{FeCl}_{3} \cdot 6 \mathrm{H}_{2} \mathrm{O}(1.18 \mathrm{~g})$ and $\mathrm{FeCl}_{2} \cdot 4 \mathrm{H}_{2} \mathrm{O}(0.43$ g) were dissolved in $200 \mathrm{~mL}$ deionized water under nitrogen gas with vigorous stirring at 60 ${ }^{\circ} \mathrm{C}$. Then 1.0 gram of MWCNTs was added in the solution with ultrasonic treatment for about 10 min. Finally, $\mathrm{NH}_{4} \mathrm{OH}$ solution was added dropwise into the solution until its $\mathrm{pH}$ was adjusted to 11 . After stirring for $30 \mathrm{~min}$ at $50{ }^{\circ} \mathrm{C}$, the obtained MWCNTs- $\mathrm{Fe}_{3} \mathrm{O}_{4}$ nanocomposite was separated from the reaction medium by magnetic field, and 
washed with $200 \mathrm{~mL}$ deionized water four times.

\subsection{Magnetic solid-phase extraction procedure}

A 100-mililiter sample or standard solution containing $\operatorname{In}(\mathrm{III})\left(\mathrm{pH}\right.$ 6), and QA $\left(1.0 \times 10^{-5}\right.$ mol L ${ }^{-1}$ ), was transferred in a glassware beaker. Then $5 \mathrm{mg}$ MWCNTs- $\mathrm{Fe}_{3} \mathrm{O}_{4}$ nanocomposite was added into the sample solution. Afterwards, the mixture was stirred for $3 \mathrm{~min}$. Subsequently, the sorbent particles were isolated by placing a strong magnet, and the supernatant was poured away. The preconcentrated target analyte was eluted using 1.0 $\mathrm{mL}$ of a $1 \mathrm{~mol} \mathrm{~L}^{-1}$ solution of $\mathrm{HNO}_{3}$. Finally, the concentration of $\operatorname{In}(\mathrm{III})$ in acidic aqueous phase was determined by ICP-OES.

\section{Results and discussion}

\subsection{Effect of $\mathrm{pH}$}

The effect of $\mathrm{pH}$ on the extraction of indium was studied in the range of 2.0-8.0 using nitric acid or sodium hydroxide. The resulting percent recovery$\mathrm{pH}$ plots are shown in Fig. 1. These plots indicate that sorption is maximum and quantitative in the $\mathrm{pH}$ range of 6.0-7.0. Consequently, a solution $\mathrm{pH}$ of 6.0 was used in further experiments.

\subsection{Effect of the sorbent amount}

In order to study the effect of the sorbent, 2 to $10 \mathrm{mg}$ of MWCNTs- $\mathrm{Fe}_{3} \mathrm{O}_{4}$ nanocomposite was added to $100 \mathrm{~mL}$ of the sample solution (Fig. 2).

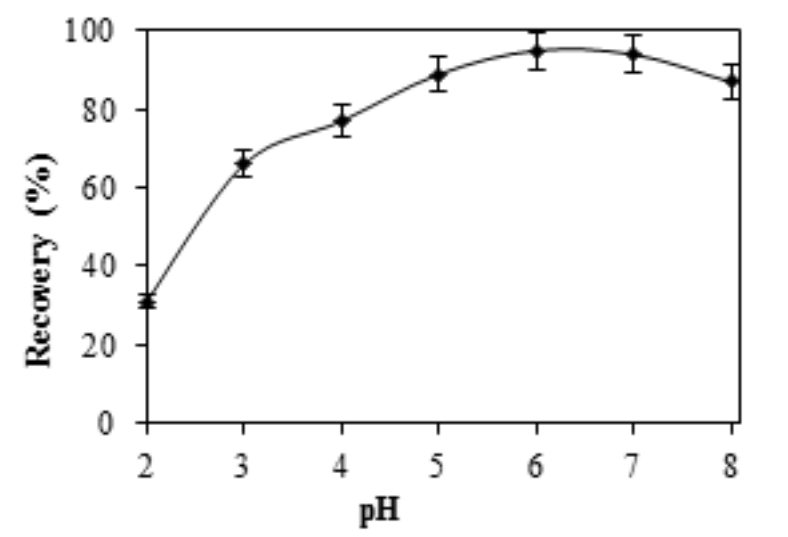

Fig. 1. Effect of $\mathrm{pH}$ on the recovery of $\mathrm{In}(\mathrm{III})$ ion.
The obtained results showed that by increasing the sorbent amounts from 2 up to $5 \mathrm{mg}$ due to increasing accessible sites, extraction recovery increased, and then it remained constant. A 5-miligram of the MWCNTs- $\mathrm{Fe}_{3} \mathrm{O}_{4}$ nanocomposite was selected for subsequent experiments.

\subsection{Effect of eluent type}

In order to find the best eluent, different eluting solutions such as $\mathrm{HCl}, \mathrm{H}_{2} \mathrm{SO}_{4}, \mathrm{HNO}_{3}$ and acetic acid, were tested. The results revealed that a 1.0-mililiter of 1.0 M concentration of all acids could afford the quantitative elution of $\mathrm{In}^{3+}$ from the sorbent. Finally, subsequent elutions of $\mathrm{In}^{3+}$ were carried out with $1 \mathrm{M} \mathrm{HNO}_{3}$ solution

\subsection{Effect of chelating reagent concentration}

The effect of QA concentration on the extraction of indium was studied, and the results are shown in Fig. 3. Also, QA concentration in the range of 0 to $5.0 \times 10^{-5} \mathrm{~mol} \mathrm{~L}^{-1}$ was investigated by us. Then, maximum recovery was obtained at a concentration of $1.0 \times 10^{-5} \mathrm{~mol} \mathrm{~L}^{-1}$ of the ligand and at higher concentrations, the extraction recovery remained constant.

\subsection{Effect of solution volume}

The effect of solution volume was examined by

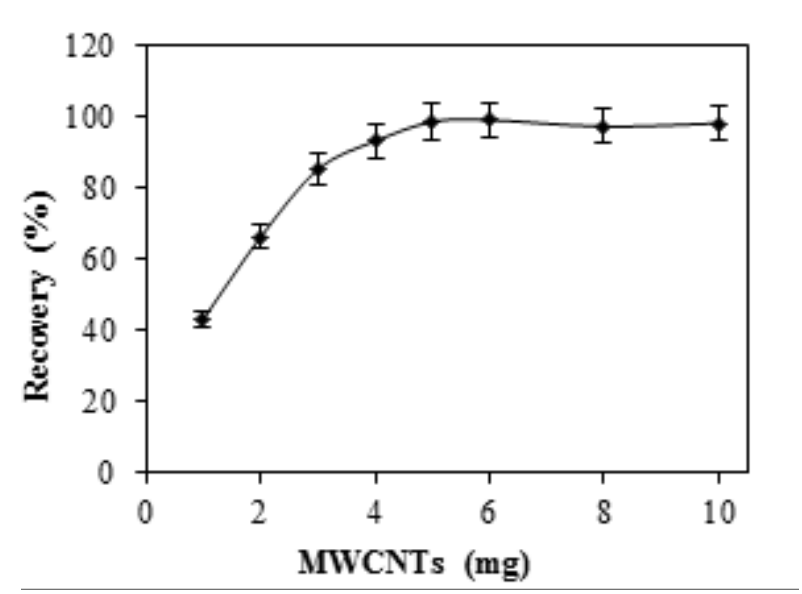

Fig. 2. Effect of the MWCNTs- $\mathrm{Fe}_{3} \mathrm{O}_{4}$ amount on the recovery of $\operatorname{In}(\mathrm{III})$ ion. 


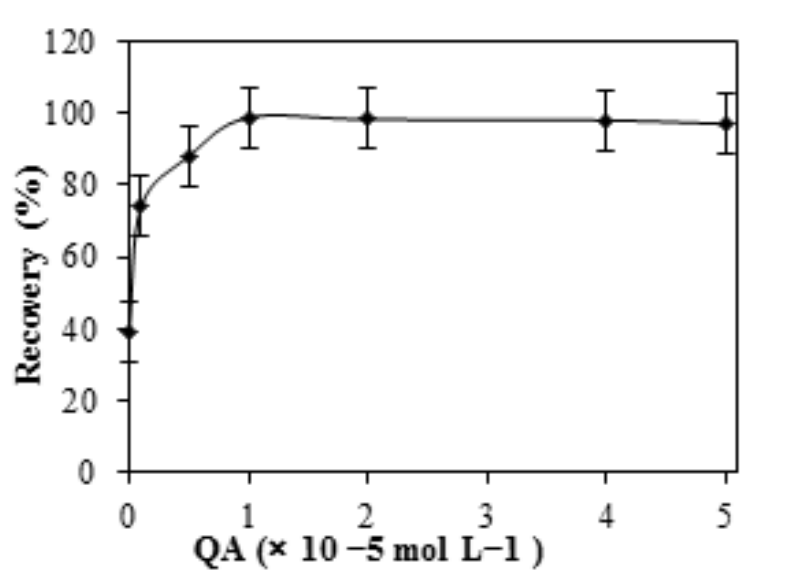

Fig. 3. Effect of chelating reagent concentration on the recovery of $\operatorname{In}(\mathrm{III})$ ion.

preconcentrating different volumes $(20-250 \mathrm{~mL})$ of aqueous solutions spiked with a constant mass of $10.0 \mu \mathrm{g}$ of $\operatorname{In}(\mathrm{III})$, and the results are depicted in Fig. 4. The obtained results showed that when aqueous solution volume was up to $100 \mathrm{~mL}$, recoveries above $95 \%$ were obtained. Thus, 100 $\mathrm{mL}$ was considered to be the maximal enrichment volume for water samples. Consequently, since the final solution volume to be measured by ICP-OES was $1.0 \mathrm{~mL}$, the preconcentration factor for In(III) was evaluated as 100 .

\subsection{Effect of extraction time}

The effect of extraction time on the extraction of

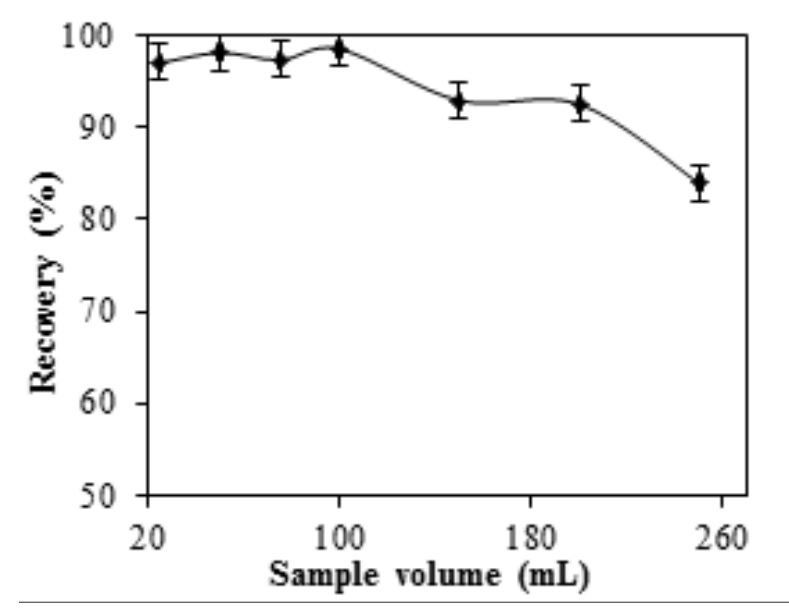

Fig. 4. Effect of sample volume on the recovery of In(III) ion.
In(III) was studied in the range of $1-15 \mathrm{~min}$. The experimental results indicated that there was no significant effect on the extraction efficiency when the extraction time increased from 3 to $10 \mathrm{~min}$. Based on the above considerations, the extraction time that is equal to $3 \mathrm{~min}$ was selected for further studies.

\subsection{Effect of diverse ions on the recovery}

In order to assess the possible analytical applications of the recommended procedure, the effect of common coexisting ions in natural water samples on the preconcentration and determination of indium ion was studied. In these experiments, 100 $\mathrm{mL}$ solutions containing $50 \mu \mathrm{g} \mathrm{L}^{-1}$ of indium and various amounts of interfering ions were treated according to the recommended procedure. In addition, tolerable limit was defined as the highest amount of foreign ions that produced an error not exceeding $\pm 5 \%$ in the determination of investigated analyte ion. The results are summarized in Table 1. As seen, a large number of ions used have no considerable effect on the determination of indium.

\subsection{Analytical figures of merit}

In Table 2, the analytical characteristics of the proposed method, including linear range, limit of detection, reproducibility, and enrichment factor have been summarized. In the optimum conditions, a calibration graph was constructed by preconcentrating a series of the solutions according to the recommended procedure. There is an important tip, that the calibration curve for In(III) was linear form 1.0 to $500 \mu \mathrm{g} \mathrm{L}^{-1}$ with a regression

Table 1. Tolerance limits of some cations and anions on the sorption and determination of indium.

\begin{tabular}{ll}
\hline Ion & Tolerance limit $\left(\mu \mathrm{g} \mathrm{mL}^{-1}\right)$ \\
\hline $\mathrm{Li}^{+}, \mathrm{Na}^{+}, \mathrm{K}^{+}, \mathrm{Cl}^{-}, \mathrm{NO}^{-}$ & $>2000$ \\
$\mathrm{Ca}^{2+}, \mathrm{Mg}^{2+}, \mathrm{Ba}^{2+}, \mathrm{Sr}^{++}$ & 1000 \\
$\mathrm{Ag}^{+}, \mathrm{Hg}^{2+}, \mathrm{SO}_{4}^{-}$ & 50 \\
$\mathrm{Cu}^{-}, \mathrm{Fe}^{3+}, \mathrm{Pb}^{2+}, \mathrm{Ni}^{2+}, \mathrm{Co}^{2+}$, & 5 \\
$\mathrm{Cr}^{3+}, \mathrm{Mn}^{2+}, \mathrm{Cd}^{2+}, \mathrm{Zn}^{2+}$ & \\
\hline
\end{tabular}


Table 2. Analytical parameters of the proposed method.

\begin{tabular}{ll}
\hline Parameter & Analytical feature \\
\hline Linear range $\left(\mu \mathrm{g} \mathrm{L}^{-1}\right)$ & $1.0-500$ \\
$\mathrm{r}^{2}$ & 0.995 \\
LOD $\left(\mu \mathrm{g} \mathrm{L}^{-1}\right)$ & 0.28 \\
R.S.D. $\%(\mathrm{n}=10)$ & 3.1 \\
Enrichment factor & 100 \\
\hline
\end{tabular}

coefficient of 0.995 . The limit of detection (LOD) of the proposed method for the determination of indium was studied under the optimal experimental conditions. The LOD, defined three times by paying attention to the standard deviation of 10 measurements of the blank solution divided by the slope of the calibration curve, was $0.28 \mu \mathrm{g} \mathrm{L}^{-1}$. The reproducibility of the proposed method for extraction and determination of $50 \mu \mathrm{g} \mathrm{L}^{-1}$ indium $(\mathrm{n}=10)$ was also studied. Finally, the relative standard deviations (R.S.D.) of these determinations were $3.1 \%$.

\subsection{Application}

The accuracy of the proposed method was tested by separation and determination of In(III) in tap water, mineral water, and well water samples. The obtained results are given in Table 3. The relative recoveries for the spiked samples were in the range of $94-109 \%$. The results demonstrated that the proposed method was suitable for the determination of In(III) in real samples.

\section{Conclusions}

In this study, a fast and simple method based was developed for the separation and preconcentration of indium, prior to ICP-OES determination. The use of NPs endued the SPE method with high extraction capacity and preconcentration factors. The magnetic separation greatly improved the separation rate while avoided the time-consuming column passing or filtration operation. The proposed preconcentration and determination method gives a low limit of detection and good R.S.D. values. Finally, the method can be successfully applied to the separation and determination of indium in real samples.
Table 3. Recovery of indium from water samples.

\begin{tabular}{lccc}
\hline Sample & \multicolumn{3}{c}{ Indium } \\
\cline { 2 - 4 } & $\begin{array}{c}\text { Added } \\
\left(\mu \mathrm{g} \mathrm{L}^{-1}\right)\end{array}$ & $\begin{array}{c}\text { Found } \\
\left(\mu \mathrm{g} \mathrm{L}^{-1}\right)\end{array}$ & $\begin{array}{c}\text { Recovery } \\
(\%)\end{array}$ \\
\hline Tap water & 0.0 & $<\mathrm{LOD}$ & - \\
& 10.0 & $9.7(1.8)^{\mathrm{a}}$ & 97 \\
Mineral water & 0.0 & $<\mathrm{LOD}$ & - \\
& 10.0 & $10.9(1.4)$ & 109 \\
River water & 0.0 & $<\mathrm{LOD}$ & - \\
& 10.0 & $9.4(2.6)$ & 94 \\
\hline
\end{tabular}

a Values in parentheses are R.S.D.s based on three replicate analyses.

\section{References}

[1] M. Souad, C. Louage, J. Yves Doisy, L. Meunier, A. Benderrag, B. Ouddane, S. Bellayer, N. Nuns, M. Traisnel, U. Maschke, Extraction of indium-tin oxide from end-of-life LCD panels using ultrasound assisted acid leaching, Ultrason. Sonochem., 40 (2018) 929-936.

[2] J. Uhrovčík, J. Lesný, Determination of indium in liquid crystal displays by flame atomic absorption spectrometry, J. Ind. Eng. Chem., 21 (2015) 163165.

[3] J.R. Dean, Practical inductively coupled plasma spectroscopy, Wiley., UK, 2005.

[4] B. Çelik, E. Akkaya, S. Bakirdere, F. Aydin, Determination of indium using vortex assisted solid phase microextraction based on oleic acid coated magnetic nanoparticles combined with slotted quartz tube-flame atomic absorption spectrometry, Microchem. J., 141 (2018) 7-11.

[5] M. Eftekhari, M. Gheibi, M. Akrami, F. Iranzad, Solid-phase extraction of ultra-trace levels of lead using tannic acid-coated graphene oxide as an efficient adsorbent followed by electrothermal atomic absorption spectrometry; response surface methodology - central composite design, New J. Chem., 42 (2018) 1159-1168.

[6] J.B. Ghasemi and E. Zolfonoun, Simultaneous spectrophotometric determination of trace amounts of uranium, thorium, and zirconium using the partial least squares method after their preconcentration by $\alpha$-benzoin oxime modified Amberlite XAD-2000 resin, Talanta, 80 (2010) 1191-1197.

[7] Y. Li, Y.C. Liu, and J. Tang, Fe3O4-A12O3 magnetic core-shell microspheres for rapid and highly specific capture of phosphopeptides with 
mass spectrometry analysis, J. Chromatogr. A, 1172 (2007) 57-71.

[8] D. Horak, B. Rittich, J.A. Safar, A. Spanova, J. Lenfeld, and M.J. Benes, Properties of RNase A immobilized on magnetic poly(2-hydroxyethyl methacrylate) microspheres. Biotechnol. Prog., 17 (2001) 447-452.

[9] J.B. Ghasemi and E. Zolfonoun, Simultaneous spectrophotometric determination of trace amount of polycyclic aromatic hydrocarbons in water samples after magnetic solid-phase extraction by using projection pursuit regression, Environ. Monit. Assess., 185 (2013) 2297-2305.

[10] A. Mehdinia, M. Ramezani, A. Jabbari, Preconcentration and determination of lead ions in fish and mollusk tissues by nanocomposite of Fe304@graphene oxide@polyimide as a solid phase extraction sorbent, Food Chem., 237 (2017) 1112-1117.

[11] R.H. Baughman, A.A. Zakhidov, and W.A. deHeer, Carbon nanotubes-the route toward
applications,Science, 297 (2002) 787-792.

[12] C. Herrero-Latorre, J. Barciela-García S. GarcíaMartín R. M. Peña-Crecente, Graphene and carbon nanotubes as solid phase extraction sorbents for the speciation of chromium: A review, Anal. Chim. Acta, 1002 (2018) 1-17.

[13] Z. Dehghani, Firouzabadi, S. Dadfarnia, A.M. Haji Shabani, M.H. Ehrampoush, E.N. Tafti, Magnetic dispersive solid phase extraction using modified magnetic multi-walled carbon nanotubes combined with electrothermal atomic absorption spectrometry for the determination of selenium, Int. J. Environ. Anal. Chem., 98 (2018) 555-569.

[14] A. Pistone, D. Iannazzo, and M. Fazio, Synthesis and magnetic properties of multiwalled carbon nanotubes decorated with magnetite nanoparticles, Physica B, 435. (2014) 88-91.

[15] A. Masotti and A. Caporali, Preparation of Magnetic Carbon Nanotubes (Mag-CNTs) for Biomedical and Biotechnological Applications, Int. J Mol. Sci., 14 (2013) 24619-24642. 